\section{Aortocaval compression in the sitting and lateral decubitus positions during extradural catheter placement in the parturient}

Peter J.D. Andrews FRCAnaes, William E. Ackerman III MD, Mushtaque M. Juneja FRCAnaes
We prospectively studied the incidence of concealed aortocaval compression in parturients at term during identification of the extradural space. Forty ASA I or II parturients, at term and in active labour, who requested extradural analgesia were randomly allocated to one of two groups. Parturients in the first group $(n=22)$ were positioned in the left lateral decubitus position and those in the second group $(n=18)$ were in the sitting position. Cardiac output (CO) was recorded at oneminute intervals for five minutes before extradural catheter placement (supine position with a $15^{\circ}$ wedge under the right side), and during and thereafter for five minutes (in the supine wedged position), using the BoMED NCCOM3-R7 thoracic electrical bioimpedance (TEB) monitor. The average of five $\mathrm{CO}_{T E B}$ recordings before positioning the patient were compared with the average of five $\mathrm{CO}_{T E B}$ measurements during and afier extradural space identification. A change of $>25 \% \quad \mathrm{CO}_{T E B}$ was considered beyond machine variability. Upper limb arterial pressure was recorded at one-minute intervals. In the lefi lateral decubitus position, 17 of 22 patients demonstrated $a>25 \%$

\section{Key words}

ANAESTHESIA: obstetrical;

ANAESTHETIC TECHNIQUES: extradural analgesia;

COMPLICATIONS: aortocaval compression.

From the Department of Anesthesiology, University of Louisville, School of Medicine, 40292, and Norton hospital, 40291, Louisville, Kentucky.

This paper was presented in part to the Society of Obstetric Anesthesiologists and Perinatologists, Charleston, South Carolina, May 7-10, 1992.

Address correspondence to: Dr. P.J.D. Andrews, Division of Anesthesia, Glasgow Royal Infirmary, Alexandra Parade, Scotland, U.K., G31 OSF. Telephone: 041-552-3535, Fax: 041-304-4622.

Accepted for publication 16th December, 1992. reduction in $\mathrm{CO}_{T E B}$ compared with five of 18 patients in the sitting position $\left(X^{2}, P<0.01\right)$. The percentage change in $\mathrm{CO}_{T E B}$ in the lateral decubitus position ( $-29.8 \%, 95 \% \mathrm{Cl}-17 \%$ to $-44 \%)$ was greater than the sitting position $(-9.8 \%, 95 \% \mathrm{CI}+36 \%$ to $-32 \%)(P<0.01)$. A decreased incidence of aortocaval compression during identification of the extradural space was demonstrated in the sitting position when compared with the left lateral decubitus position.

De façon prospective, nous avons recherché lincidence de la compression de l'aorte abdominale et de la veine cave inférieure chez de parturientes à terme pendant le repérage de l'espace péridural. Quarante patientes ASA I ou II à terme ou en travail qui désiraient une anesthésie péridurale ont été distribuées au hasard à un de deux groupes. Le parturientes du premier groupe $(n=22)$ ont été positionnées en décubitus latéral gauche et celles du deuxième groupe $(n=18)$ en position assise. Le débit cardiaque (DC) fut enregistré à la minute pendant cinq minutes avant la mise en place du catheter péridural (décubitus dorsal avec un coin soulevant le côté droite de $15^{\circ}$ ), pendant et après pour cinq minutes (toujours en décubitus avec surélévation) avec un moniteur de bioimpédance thoracique électrique Bomed CCOM3-R7 (moniteur TEB). La moyenne de cinq mesures du $D C_{T E B}$ avant le positionnement de la patiente a été comparée avec la moyenne de cinq mesures enregistrées pendant et après le repérage de l'espace épidural. On a considéré qu'un changement de plus de $25 \%$ du $D C_{T E B}$ dépassait la variabilité de l'appareil. La pression artérielle a été mesurée au membre supérieur à chaque minute. En décubitus latéral, 17 des 22 patientes ont montré une baisse $>25 \%$ de $D C_{T E B}$ en comparaison avec 5 de 18 patientes en position assise $\left(X^{2}, P<\right.$ $0,01)$. Le pourcentage de changement de $D C_{T E B}$ en décubitus latéral $(-29,895 \% \mathrm{CI}-17 \% \dot{a}-44 \%)$ est plus grand qu'en position assise $(-9,8,95 \% C I+36 \%$ à $-32 \%)(P<0,01)$. On a donc constaté une baisse de lincidence de la compression de l'aorte abdominale et de la veine cave inférieure pendant la repérage de l'espace péridural en position assise comparativement au décubitus latéral gauche. 
Hypotension due to aortocaval compression has previously been reported in the supine recumbent and lateral decubitus positions and demonstrated by cavogram. ${ }^{1}$ In the latter position this was due to flexion of the spine around the gravid uterus resulting in compression of the inferior vena cava.

The vascular bed of the uterus is described as maximally dilated and without autoregulation. ${ }^{2}$ Uteroplacental blood flow (UBF) is therefore directly related to perfusion pressure, that is, maternal mean arterial pressure (internal iliac arteries) minus uterine venous pressure (MMAP-UVP). However, maternal alpha sympathetic adrenergic stimulation is known to increase uterine vascular resistance (UVR) ${ }^{2}$ and decrease UBF. Concealed aortocaval compression will result in a decrease in MMAP, an increase in maternal sympathetic tone and an increase in UVP, with a resultant decrease in UBF.

The incidence of concealed aortocaval compression in the two positions commonly used during identification of the extradural space is unknown. The aim of this prospective randomised study was to assess the incidence of concealed aortocaval compression in the left lateral decubitus and sitting positions during identification of the extradural space in the parturient at term.

\section{Methods}

Following institutional review board approval and patient informed consent, 40 ASA I or II term parturients who had requested extradural analgesia for labour were randomly allocated into one of two groups. Parturients in the first group ( $n=22$ ) were positioned in the left lateral decubitus position and the second group $(n=18)$ were in the sitting position for identification of the extradural space and insertion of the catheter. All parturients were prehydrated with $1000 \mathrm{ml}$ lactated Ringer's solution over $30 \mathrm{~min}$, had normal upper limb arterial pressure before extradural catheter placement and were known to be at full-term of an uncomplicated singleton gestation. In our institution, obstetric policy is to withhold extradural analgesia until $4 \mathrm{~cm}$ cervical dilatation has been achieved. Therefore, all patients were in active labour and no patient had extradural analgesia withheld for the purposes of this study.

An aseptic technique, using loss of resistance to $4 \mathrm{ml}$, saline $0.9 \%$, was used to identify the extradural space. A $17 \mathrm{G}$ Tuohy needle and subsequently an $18 \mathrm{G}$ catheter were inserted at the $\mathrm{L}_{2-3}$ or $\mathrm{L}_{3-4}$ interspace. No local anaesthetic was injected into the extradural space until after completion of the study.

Maximal lumbar flexion during identification of the extradural space was achieved by asking the patient to flex her chin onto her chest and to flex her thighs onto her abdomen whilst in the left lateral decubitus position.
Lumbar flexion was achieved in the sitting position by asking the patient to flex her chin onto her chest as she sat on the bed with her legs supported on a chair at the bedside. An assistant supported the shoulders of the patient while she was encouraged to flex her lower back. No patient was helped physically to maintain either position.

As a baseline, an average of five cardiac output $\left(\mathrm{CO}_{\text {TEB }}\right)$ determinations, taken at one-minute intervals, was calculated for the five minutes before extradural catheter placement. The patients were in the supine position with a wedge under the right side to produce $15^{\circ}$ left tilt. The $\mathrm{CO}_{\text {TEB }}$ was subsequently measured during extradural space identification and catheter insertion in either left lateral decubitus or sitting positions, allowing one minute after adopting either position to reduce artifact due to movement. The average of five $\mathrm{CO}_{\text {TEB }}$ estimations, at one-minute intervals, was then calculated. Thereafter, $\mathrm{CO}_{\text {TEB }}$ was recorded at one-minute intervals for five minutes, with the patient in the supine position with $15^{\circ}$ of left tilt, using the BoMED NCCOM3-R7 monitor. ${ }^{3}$ Upper limb arterial blood pressure recordings (Dinamap 1846SX, Critikon Inc., Tampa, Fl) from the right arm were entered into CDDP software (Cardiodynamic Data Processing system, BoMED) at oneminute intervals.

\section{Cardiac output measurement}

The BoMED NCCOM3 measured stroke volume (SV), basal impedance (Z0), and cardiac output (Q) (from heart rate and SV) using an algorithm based on the SramekBernstein formula: ${ }^{4-7}$

$\mathrm{SV} \simeq \delta\left(\frac{[0.17 \mathrm{H}]^{3}}{4.2}\right) \operatorname{LVET} \frac{\left(\frac{\mathrm{dZ}}{\mathrm{dt}}\right)_{\max }}{\mathrm{Z}_{0}}$

(Delta is a scaling factor proportional to the ratio of observed weight: ideal weight; $\mathrm{H}=$ height in $\mathrm{cm}$; LVET $=$ left ventricular ejection time; $Z=$ impedance.)

Two sensing electrode pairs were placed on the thorax at the level of the xiphisternum in the mid-axillary line and on the lateral aspect of the neck above the clavicles. The other two pairs of current-introducing electrodes were placed $5 \mathrm{~cm}$ above the cervical electrodes and 5 $\mathrm{cm}$ below the thoracic sensing electrodes. The currentintroducing electrodes delivered $2.5 \mathrm{~mA}$ at $70 \mathrm{kHz}$ alternating current (AC). At this frequency tissue is not excitable. The BoMED NCCOM3 monitor averaged data from 16 beats and all digital data were output to an IBM personal computer and stored using CDDP software. Statistical comparisons were made with the average of five cardiac output determinations which in turn were 
an average of 16 cardiac cycles. Therefore, the effect of uterine contractions upon these averaged cardiac output determinations was reduced and similar for each determination.

A change in posture may alter basal thoracic impedance and invalidate observed alterations in $\mathrm{CO}_{\mathrm{TEB}}$. Therefore, after changing position, to sitting or lateral decubitus from the supine wedged position, recordings were scrutinized for a change in basal impedance (Z0) and only those with a change in $\mathrm{Z0}$ of $5 \%$ or less were accepted, ${ }^{7}$ (Table III).

It has been demonstrated that there is clinically satisfactory agreement between measurements previously made using thermodilution $\left(\mathrm{CO}_{\mathrm{TD}}\right)$ and $\mathrm{CO}_{\mathrm{TEB}}$ in pregnant and non-pregnant patients. ${ }^{8-11}$ The $\mathrm{CO}_{\mathrm{TD}}$ has been shown to have an overall error of $15-20 \%$ in the clinical setting ${ }^{12,13}$ and therefore only changes in $\mathrm{CO}_{\text {TEB }}$ of greater than $25 \%$ of the baseline value were considered to represent a genuine change in cardiac output.

\section{Data analysis}

A power analysis was performed to determine the sample size necessary to detect a difference of $25 \%$ in $\mathrm{CO}_{\mathrm{TEB}}$ between the two groups, with $95 \%$ confidence of detecting a true difference. Mean and standard deviations for this calculation were taken from data collected during routine monitoring of a similar population of parturients. It was determined that 14 patients would be required to meet our need.

$n=2\left(\frac{\left(\mathrm{Z}_{\alpha}-\mathrm{Z}_{\beta} \times \sigma\right.}{\left(\mathrm{Mn}_{1}-\mathrm{Mn}_{2}\right)}\right)^{2}$

( $n=$ number.required; $\mathrm{Z}_{\alpha}=1.96 ; \mathrm{Z}_{\mathrm{B}}=-0.95 ; \sigma=2.027$ $\mathrm{L} \cdot \min ^{-1}$; (mean.group 1 - mean.group 2) $\mathrm{Mn}_{1}-\mathrm{Mn}_{2}$ $\left.=2.22 \mathrm{~L} \cdot \mathrm{min}^{-1}\right)$

We studied 40 patients, randomly allocated to lateral decubitus or sitting positions, to reduce the false negative rate.

The data were analyzed using ANOVA, Mann Whitney Wilcoxon test (MWW), correlation analysis, and chi square test $\left(\mathrm{X}^{2}\right)$ where appropriate and the results are presented as median and interquartile range [] unless otherwise stated.

\section{Results}

There were no differences in demographic data between the two groups (ANOVA) Table I.

In the lateral decubitus position 17 of 22 of patients (77\%) demonstrated $>25 \%$ reduction in $\mathrm{CO}_{\mathrm{TEB}}$ compared with five of $18(27 \%)$ in the sitting position $\left(\mathrm{X}^{2}, P<\right.$ 0.01). The percentage decrease in $\mathrm{CO}_{\text {TEB }}$ in the left lateral decubitus position was greater than in the sitting
TABLE I Demographic data

\begin{tabular}{lll}
\hline & $\begin{array}{l}\text { Lateral decubitus } \\
\text { position }\end{array}$ & $\begin{array}{l}\text { Sitting } \\
\text { position }\end{array}$ \\
\hline Height $(\mathrm{cm})$ & $160.6(6.23)$ & $161(6.21)$ \\
BSA $\left(\mathrm{m}^{2}\right)$ & $1.74(0.11)$ & $1.79(0.12)$ \\
Age $(\mathrm{yr})$ & $23.6(3.1)$ & $25.2(2.3)$ \\
Weight $(\mathrm{kg})$ & $73.3(6.5)$ & $74.8(5.8)$ \\
cm dilated & $4[3-5]$ & $4[3-5]$ \\
Gestation $(\mathrm{wk})$ & $39.7(1.9)$ & $39.4(1.6)$ \\
\hline
\end{tabular}

Mean and (SD).

Median and [range].

TABLE II Haemodynamic variables

\begin{tabular}{lll}
\hline & $\begin{array}{l}\text { Sitting } \\
\text { position }\end{array}$ & $\begin{array}{l}\text { Lateral decubitus } \\
\text { position }\end{array}$ \\
\hline PreCO $_{\text {TEB }}$ & $8.5(2.3) \mathrm{L} \cdot \mathrm{min}^{-1}$ & $9.28(1.7) \mathrm{L} \cdot \mathrm{min}^{-1}$ \\
PerCO $_{\text {TEB }}$ & $7.8(2.1) \mathrm{L} \cdot \mathrm{min}^{-1}$ & $6.5(1.2) \mathrm{L} \cdot \mathrm{min}^{-1}$ \\
PstCO $_{\text {TEB }}$ & $8.1(1.9) \mathrm{L} \cdot \mathrm{min}^{-1}$ & $8.89(2.1) \mathrm{L} \cdot \mathrm{min}^{-1}$ \\
PreAP & $85.8(16.3) \mathrm{mmHg}$ & $88.5(12.9) \mathrm{mmHg}$ \\
PerAP & $83.4(11.4) \mathrm{mmHg}$ & $86.7(12.3) \mathrm{mmHg}$ \\
PstAP & $82.4(10.3) \mathrm{mmHg}$ & $78.5(15.9) \mathrm{mmHg}$ \\
& & $95.1(14.9) \mathrm{bpm}$ \\
PreHR & $96.3(15.4) \mathrm{bpm}$ & $92.3(15.9) \mathrm{bpm}$ \\
PerHR & $91.5(6.5) \mathrm{bpm}$ & $86.1(12.5) \mathrm{bpm}$ \\
PstHR & $84.9(11.4) \mathrm{bpm}$ &
\end{tabular}

$\mathrm{CO}_{\text {TEB }}$, cardiac output by thoracic electrical bioimpedance; $\mathrm{HR}$, heart rate; AP, mean arterial pressure: Pre, mean value before positioning for identification of the extradural space; Per, mean value during extradural space identification; Pst, mean value during $5 \mathrm{~min}$ after returning to supine position with left $15^{\circ}$ tilt: Mean and (standard deviation), Median and IQR [inter-quartile range].

position (MWW, $\mathrm{Z}=2.68$; average rank for sitting was $9.8 \%$ and for lateral position $29.8 \% ; n=18$ and 22 respectively, $P<0.01$ ). There was no relationship between body surface area (BSA) and reduction in $\mathrm{CO}_{\mathrm{TEB}}$ in either the lateral or sitting positions (lateral, corr coef $=0.266$, $\mathrm{SEE}=24.5,21 \mathrm{DF}, P=\mathrm{NS}$; sitting, corr coef $=0.08$, $\mathrm{SEE}=13.17,17 \mathrm{DF}, P=$ NS). No changes in heart rate or upper limb arterial pressure were recorded in either group. There were no differences in these variables between groups (Table II and III). No patient exhibited revealed aortocaval compression (hypotension associated with aortocaval compression ${ }^{14}$ ).

After returning to the supine position with $15^{\circ}$ left lateral tilt, $\mathrm{CO}_{\mathrm{TEB}}$ reverted to baseline values in all cases. There were no differences between the pre-extradural space identification and post-extradural space identification average $\mathrm{CO}_{\text {TEB }}$ (MWW).

The $\mathrm{Z} 0$ remained within $5 \%$ of baseline in all patients one minute after positioning for extradural space identification (Table III). 
TABLE III Cardiac output and impedance changes

\begin{tabular}{lll}
\hline & $\begin{array}{l}\text { Sitting } \\
\text { position }\end{array}$ & $\begin{array}{l}\text { Lateral decubitus } \\
\text { position }\end{array}$ \\
\hline $\mathrm{DCO}_{\text {TEB }}$ & $-0.8 \mathrm{~L} \cdot \mathrm{min}^{-1}$ & $-3.2 \mathrm{~L} \cdot \mathrm{min}^{-1}$ \\
IQR & {$[-3.8 ; 2.2] \mathrm{L} \cdot \mathrm{min}^{-1}$} & {$[-4.8 ;-1.3] \mathrm{L} \cdot \mathrm{min}^{-1}$} \\
\%DCO & $-9.8 \%$ & $-29.8 \%$ \\
IQR & {$[-32$ to +36$] \%$} & {$[-44$ to -17$] \%$} \\
& & $18.5(1.9)$ \\
PreZ0 & $19.4(2.3)$ & $18.9(2.3)$ \\
PerZ0 & $17.8(2.6)$ & $17.5(2.9)$ \\
\hline PstZ0 & $18.5(1.9)$ &
\end{tabular}

$\mathrm{DCO}=$ change in cardiac output; $\% \mathrm{DCO}$, percentage change in cardiac output; $\mathrm{Z0}$, basal thoracic electrical bioimpedance; Pre, mean value before positioning for identification of the extradural space; Per, mean value during extradural space identification; Pst, mean value during 5 min after returning to supine position with left $15^{\circ}$ tilt: Mean and (standard deviation), Median and IQR [inter-quartile range].

\section{Discussion}

In a recent study neither position, sitting or left lateral decubitus, was preferred by the majority of term parturients. ${ }^{15}$ However, we have shown that the left lateral decubitus position with pronounced flexion of the spine ("fetal curl" position) may cause concealed aortocaval compression during extradural space identification. In the lateral position aortocaval compression is probably due to flexion of the spine around the gravid uterus and is exacerbated by the patient's thighs exerting a backward force upon the uterus. In the sitting position, with the patient leaning forward, the pregnant uterus will be displaced forward. Therefore although the lateral position is recommended ${ }^{16}$ throughout pregnancy, the tight fetal curl position ought to be avoided.

Obstruction of the inferior vena cava causes a decrease in maternal cardiac output and an increase in venous pressure below the obstruction. ${ }^{17}$ Compression of the aorta occurs above the origin of the internal iliac arteries $^{18}$ and may combine with the effects of venous obstruction to decrease utero-placental perfusion pressure and blood flow. ${ }^{2,19,20}$ In our study, arterial pressure was measured in the right arm; however, measurement in the leg may be more appropriate and might detect aortic compression. $^{21}$

Although the use of the BoMED NCCOM3 monitor has been reported in the parturient, there are theoretical problems with using TEB during labour. A change in the position of the parturient may cause a change in the position of the diaphragm and therefore the composition of the volume of electrically participating tissue. A change in Z0, resistivity, and stroke volume would then follow.

Furthermore, movement of the parturient will result in a change in the thoracic length (sensing interelectrode distance), the only variable in the equation not derived from the impedance waveform. An error in this value is of importance as it appears to the third power in the Sramek-Bernstein equation (0.17.height) ${ }^{3}$. A change in thoracic length of $1 \mathrm{~cm}$ will result in a $10 \%$ error in $\mathrm{CO}_{\text {TEB }}$. However, small changes in voltage sensing interelectrode distances $(2$ to $3 \mathrm{~cm}$ ) produce equivalent changes in magnitude upon the values of $(\mathrm{dZ} / \mathrm{Dt})_{\max }$ and $\mathrm{Z}_{0}$. Thus, the ratio of $(\mathrm{dZ} / \mathrm{dT})_{\max } / \mathrm{Z}_{0}$ does not vary significantly in spite of alterations in voltage sensing interelectrode distances. ${ }^{7}$

Basal thoracic impedance $\left(\mathrm{Z}_{0}\right)$ was found to fluctuate less than $5 \%$ of baseline in our study and therefore did not contribute to the observed changes in $\mathrm{CO}_{\mathrm{TEB}}$. This concurs with the work of Milsom et al. " who demonstrated that $\mathrm{CO}_{\text {TEB }}$ was unaffected by position of the parturient.

The $\mathrm{CO}_{\text {TEB }}$ has been shown to be unreliable in septicaemic patients where shunting of blood through blood vessels in the skin is believed to occur. Under these conditions, the thorax is thought to act as a shell conductor rather than a volume conductor, ${ }^{22}$ where blood (low resistivity) in the dilated peripheral vessels significantly contributes to impedance. A similar error may occur when intravenous. oxytocin, a potent vasodilator, ${ }^{23}$ is commenced during the hyperdynamic circulation of labour. Of the patients who demonstrated a reduction in $\mathrm{CO}_{\text {TEB }}$, only one patient (lateral decubitus position) received an infusion of oxytocin; however, the dosage used to augment labour is small and the cardiovascular effects are likely to be negligible.

In summary concealed aortocaval compression occurs commonly during extradural space identification. In our study, concealed aortocaval compression occurred more frequently in the left lateral decubitus position with pronounced flexion of the spine than in the sitting position. We therefore recommend that extradural space identification be accomplished in the sitting position and where compromise of the uteroplacental unit is suspected, that the tight fetal curl position be avoided.

\section{References}

1 Scott $D B$. Inferior vena cava occlusion in late pregnancy and its importance in anesthesia. Br J Anaesth 1968; 40: 120-5.

2 Ostheimer $G W(E d$.). Manual of Obstetric Anesthesia, 2nd ed, London, New York, Melbourne, Tokyo: ChurchillLivingston Inc. 1992, 32-7.

3 Jewkes C. Sear JW, Verhoeff F, Sanders DJ, Foëx $P$. Noninvasive measurement of cardiac output by thoracic electrical bioimpedance: a study of reproducibility and comparison with thermodilution. Br J Anaesth 1991; 67: 788-94.

4 Clancy TV, Norman K, Reynolds $R$, Covington D, Maxwell JG. Cardiac output measurement in critical care pa- 
tients: thoracic electrical bioimpedance versus thermodilution. J Trauma 1991; 31: 1116-9.

5 Quail $A W$, Traugot FM, Porges WL, White SW. Thoracic resistivity for stroke volume calculation in impedance cardiography. J Appl Physiol 1981; 50: 191-5.

6 Gambling DR, Flanagan ML, Huckell VF, Lucas $S B$, Kim $J H K$. Anaesthetic management and non-invasive monitoring for Caesarean section in a patient with cardiomyopathy. Can J Anaesth 1987; 34: 505-8.

7 Bernstein DP. A new stroke volume equation for thoracic electrical bioimpedance: theory and rationale. Crit Care Med 1986; 14: 904-9.

8 Maski DI; Greenspoon JS, Ouzounian JG. Measurement of cardiac output in pregnancy by thoracic electrical bioimpedance and thermodilution. A preliminary report. Am J Obstet Gynecol 1989; 161: 680-4.

9 Appel PL, Kram HB, Mackabee J, Fleming AW, Shoemaker WC. Comparison of measurements of cardiac output by bioimpedance and thermodilution in severely ill surgical patients. Crit Care Med 1986; 14: 933-5.

10 Preisier JC, Daper A, Parquier J-N, Contempre B, Vincent $J-L$. Transthoracic electrical bioimpedance versus thermodilution technique for cardiac output measurement during mechanical ventilation. Intensive Care Med 1989; 15: 221-3.

11 Milsom I, Forssman L, Sivertsson $R$, Dottori $O$ Measurement of cardiac stroke volume by impedance cardiography in the last trimester of pregnancy. Acta Obstet Gynecol Scand 1983; 62: 473-9.

12 Stevens JH, Raffin TA, Mihm FG, Rosenthal MH, Stetz $C W$. Thermodilution cardiac output measurement: effects of respiratory cycle on its reproducibility. JAMA 1985; 253: 2240-2.

13 van Grondelle A, Ditchey RV, Groves BM, Wagner WW Jr., Reeves JT. Thermodilution method overestimates low cardiac output in humans. Am J Physiol 1983; 245 : H690-2.

14 Crawford $J S$, Burton $M$, Davies $P$. Time and lateral tilt at Caesarean section. Br J Anaesth 1972; 44, 477-81.

15 Vincent $R D$, Chestnut $D H$. Which position is more comfortable for the parturient during identification of the epidural space? International Journal of Obstetric Anaesthesia 1991; 1: 9-11.

16 Kinsella SM, Whitwam JG, Spencer JAD. Reducing aortocaval compression: how much tilt is enough? BMJ 1992, 305, 539-40.

17 Goodlin RC. Importance of the lateral position during labor. Obstet Gynecol 1971; 37: 698-701.

18 Bieniarz J, Crottogini JJ, Curuchet E et al. Aortocaval compression by the uterus in late human pregnancy. Am $\mathbf{J}$ Obstet Gynecol 1968; 100: 203-17.

19 Rankin JHG, McLaughlin MK. The regulation of the placental blood flow. J Dev Physiol 1979; 1: 3-30.
20 Eckstein K-L, Marx GF. Aortocaval compression and uterine displacement. Anesthesiology 1974; 40: 92-6.

21 Marx GF, Husain FJ, Shiau HF. Brachial and femoral blood pressures during the prenatal period. Am J Obstet Gynecol 1980; 136: 11-3.

22 Bernstein DP. Noninvasive cardiac output measurement. In: Shoemaker, Thompson, Holbrook (Eds.). Textbook of Critical Care, Philadelphia: WB Saunders, 1989: 159-85.

23 Weis FR Jr., Markello R, Mo B, Bochiechio P. Cardiovascular effects of oxytocin. Obstet Gynecol 1975; 46: 211-4. 